\title{
Effects of Dam Gate Geometry on Pressure Variation Aided by Map Presentation
}

\author{
Sheeraz M. Ameen ${ }^{1 *}$, Thamir M. Ahmed ${ }^{2}$ \\ ${ }^{1}$ Department of Petroleum (Operation and Control), Koya Technical Institute, Erbil Polytechnic University, Erbil, Kurdistan Region, Iraq, \\ ${ }^{2}$ Department of Civil Engineering, Tishk International University, Erbil, Kurdistan Region, Iraq
}

\begin{abstract}
${ }^{*}$ Corresponding author: Sheeraz M. Ameen, Department of Petroleum (Operation and Control), Koya Technical Institute, Erbil Polytechnic University, Erbil, Kurdistan Region, Iraq. E-mail: sheeraz.ameen@ epu.edu.iq
\end{abstract}

Received: 01 February 2020

Accepted: 23 June 2020

Published: 30 December 2020

\section{DOI}

10.25156/pti.v10n2y2020.pp44-52

\section{A B S T R A C T}

The dam vertical lift gate is one of the most important operational parts that regulate the high head water flow to power plants as well as satisfying the water needs for projects and areas downstream of the dam. Due to the high water levels in the dam reservoir, the gates are subjected to many hydrostatic and dynamic pressures that affect their performance and stability. Hence, it became necessary to study all parameters that may cause excessive pressures which may lead to reduce the gate performance efficiency or even cause failure. In the current study, the pressure distribution along the bottom surface of various gate lip shapes has been measured and presented as contour maps using Surfer software. The pressure fluctuation was observed to indicate the intensity of flow separation and reattachment which, in turn, causes a vibration that may threaten the stability of the gate or impede its proper functioning. The pressures in this study are expressed as a dimensional coefficient through the integration of pressure measurements at 8 points distributed over the bottom gate surface. The high intensity of pressure attachment indicates the critical condition for hydraulic design.

Keywords: Bottom pressure coefficient; Downpull force; Flow pattern; Lip gate shapes; Vertical lift gate

\section{INTRODUCTION}

Due to the operational importance of the gate and the challenges that may face due to the pressures arising by high heads of water levels in the dam reservoir, the study of the basic factors that govern the safe design has become essential to avoid any risks resulting from improper operation of the gate. One of the major factors is the pressure created on the gate bottom surface as a result of the water flow passing the gate opening, which may prevent the gate from closing in case of exceeding its permissible limits.

The pressures underneath the gate are mostly expressed by a non-dimensional term called bottom pressure coefficient $(\mathrm{Kb})$. The $\mathrm{Kb}$ is influenced by many parameters, including flow characteristics, gate lip geometry, gates opening, and pressure heads before and after the gate shaft (Sagar, 1978). Donald, 1959, studied the parameters influencing the coefficients of pressure and the relevant downpull forces on the high head gate using the compression area calculation. It was concluded that not all parameters that control the hydraulic downpull forces on the gates were identified at a level that would allow for a precise mathematical analysis of each problem. Moreover, measurement investigations are of great importance to the engineer in solving these problems.
A non-dimensional relationship that scales hydrodynamic forces has been developed to reflect the effect of ventilation, the geometry of the bottom of the gate, and the clearance of the shaft on the gate from the stability of the gate (Colgate, 1960). The effects of flow rates and high leaf gate geometries on hydraulic forces exerted on as results from upper and lower pressure coefficients have been assessed by Naudascher et al., 1964. The following formula is expressed to estimate the bottom pressure coefficient:

$$
K_{b}=\frac{2 g\left(H_{i}-H_{d}\right)}{V_{j}^{2}}
$$

Where:

$K_{b}$ : Bottom pressure coefficient

$H_{i}$ : The piezometric head at each tap,

$H_{i}$ : Piezometric head at downstream of gate shaft, and

$V_{j}$ Jet velocity issued below the gate.

Many tests using five proposed lip gate forms and other nine basic forms have been made by Elder and Garrison, 1964. In these tests, the mechanical system subjected to oscillation and observed whether the gate will fail to close. The tests revealed some difficulties due to the large hydraulic forces resulting from the use of such lip forms. 
The study concluded that the new shape of the gate resulting from the composition of the lips turns into an acceptable design.

Many experimental works have been conducted by Sagar, 1977 , to evaluate the whole forces exerted by water flow on the vertical lift gate. The study based on the Fort Randall Dam data and concluded that two major forces affect the performance of the dam gate, one resulting from the water flow below the gate and the other from the flow above the top gate surface. The difference between these two forces proposed two experimental methods for evaluating the lower force; the precipitation coefficient method based on and the pressure distribution method based on an estimate of the overall forces operating on the upper and lower gate surfaces. These two experimental methods are restricted and can only be applied to shapes similar to those used in developing formulas.

The downpull force is also expressed as shown below (Sagar, 1977):

$$
F_{d}=F_{t}-F_{b}
$$

where

$F_{d}$ : Downpull force $(\mathrm{N})$,

$F_{t}$ Force at the gate top surface $(\mathrm{N})$, and

$F_{b}$ : Force on the gate bottom surface $(\mathrm{N})$.

The effect of many parameters on downpull force is studied by Peter and Garrison, 1964. The gate geometries, flow rates, and speeds of gate closure are examined using physical hydraulic models. It is found that the variation of gate closing speed with range $(2.4-3.6 \mathrm{~m} / \mathrm{min})$ had less effect on downpull force and its maximum value on closing the moving gate was $74-79 \%$ of that on the case of the stationary gate. Many approach flow condition effects on local pressures and the behavior of flow pattern along the bottom surface of intake gates have been studied by Thang and Naudascher, 1983. The study included the use of Doppler laser anemometer and the results showed that the instability instances are indicated near the separation point at the bottom of the gate. The study concluded that the performance efficiency is influenced by the sensitivity of the discrete flow pattern which may lead to release unstable streamlines and threats the gate stability.

The pressure fluctuations on the different geometric shapes of the vertical lifting gates were examined by Bhargava and Narasimhan, 1989. The study included measurements and analysis of several hydraulic parameters affecting the values and distribution of pressure along the bottom gate surface. In the distribution pattern deviation, the spatial correlations and the intensity of pressure fluctuations were studied when the gate was forced to vibrate with one degree of freedom in the vertical direction of the quarterly frequencies and amplitude. The study revealed the prevailing frequency pressure, which is a critical condition for the design of hydraulic control gates.

The behavior of the lifting gates of different geometries and flow rates was studied under unstable load conditions (Thang, 1990). The flow fluctuation between full separation and reinstallation along the bottom gate surface was observed, and accordingly, the gate vibrations occurred in specific ranges of the dimensionless speed. The excitation mechanism is created as a result of the combined effects of both instability of the shear layer and the induced pulses in the front edge of the bottom of the gate.

The effects of many gate geometrical forms with different width gap ratios on the hydraulic force are examined by Ahmed, 1999. The study is based on the analyses of results obtained from experimental tests conducted using the arbitrary hydraulic model. The study found that the downpull coefficient is influenced significantly by gate geometry and gate openings.

The effect of numerous tailwater flow conditions on downpull was investigated by Drobir et al., 2001, proposing the hydraulic model of tunnel type - high head gate. In this model, the measurements were carried out for free and submerged flow behind the gate shaft. The experimental results were compared with those attained from the method of calculation subjected by Naudascher (1991).

The 2D CFD model was implemented by Alhashimi et al., 2010, to predict downpull coefficients (KT and KB). The finite volume method is used based on the average Reynolds Navier-Stokes equations to simulate the effect turbulence on the behavior of pressure distribution along the gate surfaces. The simulation model is used for the relevant experimental data obtained from hydraulic model tests on nine gate lip shapes conducted by Ahmed, 1999. It was found that the minimum positive downpull force can be reached for lip shape with $\theta=35^{\circ}$.

The distribution of pressure around the bottom of the outlet leaf gate and its prospective risk of cavitation and critical vibrations of the gates was studied by Khosrojerdi, 2012. The study based on the three-dimensional simulation of numerical method which was used to indicate the change in pressure and downpull forces during the vertical gate movements. It is found the downpull forces influenced by the upward and downward direction of gate movements. The method that can be used to estimate the downpull forces on the intake gates which is fitted to a hydropower plant is suggested by Uysal, 2014. It is concentrating on 
the evaluation of downpull forces for several closure rates and gate lip geometries. The results are compared with outcomes that were attained using ANSYS FLUENT programming as a tool for calculation. Downpull coefficients that have been got from the computational study confirmed a great agreement with those obtained from measurements.

Many previous studies showed that the bottom pressure coefficient is the most effective parameter on values of downpull force estimation. Relevant parameters that influence the bottom pressure factor are expressed by the following form (Ahmed, 2016):

$$
K_{b}=f\left(\frac{X}{D}, H_{i}, H_{d}, \frac{V_{j}^{2}}{2 g}, \frac{Y}{Y_{o}}\right)
$$

Where

$K_{b}: K_{b}$ : Bottom pressure coefficient,

$\frac{X}{D}$ : Distance ratio along bottom gate surface, where $\mathrm{X}$ is

$D$ the tap distance from leading edge and $\mathrm{D}$ is the gate thickness,

$\frac{Y}{Y}$ : Gate opening ratio, where $\mathrm{y}$ is the gate opening and

$Y_{\circ}$ Yo is the height of the tunnel,

$H_{i}$ Piezometric head on bottom gate surface,

$\frac{V_{j}^{2}}{2 g}$ : Jet velocity head, and

$H_{d}$ Piezometric head downstream gate shaft.

It is found from the previous studies that limited works have been conducted to investigate the effect of gate lip shapes with small angles on flow behavior and continuously on pressure impact which both represents major parameters affected gate performance and stability. In the present study, several laboratory experiments were carried out to demonstrate the effect of two types of gate lip shapes with small angles $\left(\theta=15^{\circ}\right.$ and $\left.\theta=20^{\circ}\right)$ on the values and pressure distribution of flow created under the dam gate using a random hydraulic model. The research included conducting pressure measurements in a set of points that were distributed regularly on the bottom gate surface. Hence, the results were analyzed by studying the behavior of the flow pattern beneath the gate and its effect on the stability and performance of the gate.

\section{EXPERIMENTAL WORK}

The experiments were carried out using a random hydraulic model designed by Ahmed, 1999, and constructed at the Hydraulic Laboratory of the International Tshik University/Erbil/Iraq. The model consists of a rectangular recycling flume, $4 \mathrm{~m}$ long, $0.2 \mathrm{~m}$ wide, and $0.3 \mathrm{~m}$ deep. The bed and sides of the flume were made of glass and covered along the top by a thick plate sheet representing the roof of the tunnel. The steel gate pillar $(0.3 \times 0.15 \times$ $0.06 \mathrm{~m}$ ) is installed halfway above the flat roof. The tunnel head was fed with a static tank to minimize the effects of disturbance. The flow is returned to the storage tank through the control gate that is installed at the end tunnel. The control gate is necessary to provide a pressurized condition for all different flow conditions that have been considered for this study. The AC motor was used to drive a $4 \mathrm{KW}$ pump, thus providing discharge set by a valve. The main measuring instruments of the hydraulic model are shown in Figure 1, and the gate details are shown in Figure $2 \mathrm{a}$ and $\mathrm{b}$.

The gate with two exchangeable lip forms, $\left(\theta=15^{\circ}\right.$ and $\theta=20^{\circ}$ ), was manufactured using a thick steel plate. The pressure can be measured with eight piezometric holes spread over two parallel lines along the bottom gate surface. These two sets of taps are installed at distances of $0.25 \mathrm{~B}$ and $0.5 \mathrm{~B}$ from the right edge of the gate with an equal interval distance from each other; then, all have been connected to the manometer panels through plastic tubes.

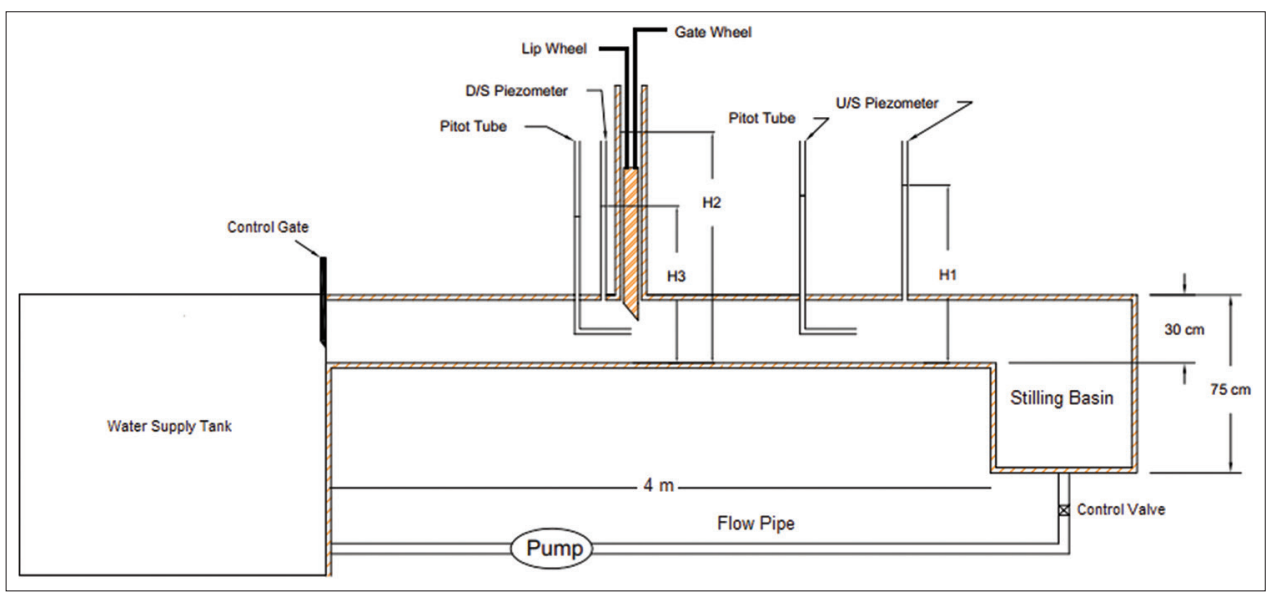

Figure 1: Schematic hydraulic model 


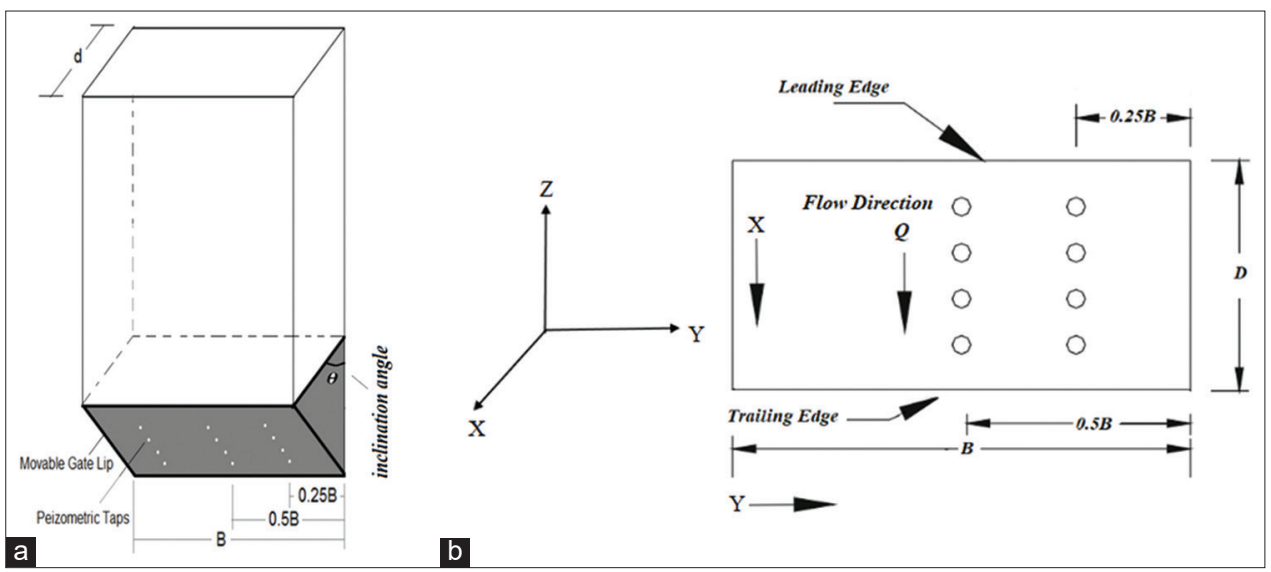

Figure 2: (a) Gate model. (b) Bottom gate surface with piezometric taps

The pressure head for all eight taps has been measured and the bottom pressure coefficient $\mathrm{Kb}$ can be obtained using Equation 1. The contour maps of the pressure were constructed using Surfer software 14. The construction of the contour map needs the coordinates of each tap $(X / D$, $\mathrm{Y} / \mathrm{B}$ ) and its corresponding value of $\mathrm{Kb}$. The dimensional distance of each tap $\mathrm{X} / \mathrm{D}$ was measured from the gate leading edge and $\mathrm{Y} / \mathrm{B}$ from the right edge of the gate, as shown in Figure $2 \mathrm{~b}$.

Pressure distribution on the two lift gate geometries $\left(\theta=15^{\circ}\right.$ and $\left.\theta=20^{\circ}\right)$ was measured and analyzed aided by contour map constructed using Surfer Software. The gate lip shape can be characterized as a principal factor affecting the distribution of pressure arising from the flow issued beneath the gate. The behavior of flow lines may be alternated along the bottom gate surface between attachments and detachments. Such a phenomenon may cause the gate to vibrate that could threaten its stability and safe operation. The influence of different hydraulic parameters and gate openings on the pressure distribution along the bottom gate surface was examined. Different three-dimensional distribution patterns of pressure were studied. The total intensity of the fluctuation pressures on the stationary gates was obtained by integrating pressure on the gate thickness. The flow pattern is studied below the gates for different geometric shapes through various gate openings. Distinguishing features of the flow pattern are the flow separation and the mean location of reinstallation was detected by visual observation. According to the basis of the flow lines behavior and the values of the bottom pressure coefficient $(\mathrm{Kb})$, the cases of attachment and discrete flow from the bottom gate surface can be identified. All positive values of $\mathrm{Kb}$ can be considered as a case of attachment with various degrees of impact, whereas the negative values represent the separation phenomenon which may be associated by forming a relatively small vortex pocket under the gate.

\section{Bottom Pressure Coefficient for Gate Lip Shape} $\left(\theta=15^{\circ}\right)$

It can be noted that in the case of small openings $\left(\mathrm{Y} / \mathrm{Yo}_{\mathrm{O}}=10 \%\right)$ for gate lip shape $\left(\theta=15^{\circ}\right)$, the pressure values are relatively high and mostly concentrated in the middle of the front part of the bottom gate surface and decrease regularly from the rest of the gate portions to be at their minimum values and even negative in the middle of the gate which represented by $\mathrm{X} / \mathrm{D}=0.35$ up to 0.7 in addition to front corners of gate [Figure 3]. Such variation considerably indicated that the streamlines were kept attached with different degrees of impact over the bottom gate surface except for the middle zone when the separation occurs.

The increase in gate openings $(\mathrm{Y} / \mathrm{Yo}=70 \%)$ caused gradual changes in flow patterns and hence affected the pressure values and distribution over the entire surface of the gate. It can be seen from Figures 4- 8 that the drop-in pressure to negative values is clearly observed and the lowest values were mostly concentrated in the middle zone. The establishment of separation along and across the bottom gate surface leads to an increase in the downpull force which, in turn, may threaten the gate operation. This finding is in agreement with Sagar, 1977, and Ahmed, 1999. A relative increase in pressure values has been shown as gate openings increase to be more than $\mathrm{Y} / \mathrm{Yo}=70 \%$. Such an increase in the bottom pressure coefficient $(\mathrm{Kb})$ is shown in Figures 9 and 10. As constant flow rate was used, no significant fluctuation in pressure is found due to the change of gate opening and then, the vibration was not initiated.

\section{Effect of Increased Discharge on the Pressure Distribution for $\theta=15^{\circ}$}

The effect of increased discharge on the values and distribution of the pressure coefficient $(\mathrm{Kb})$ for gate lip shape $\left(\theta=15^{\circ}\right)$ was studied in this study. The results have shown that increased discharge has a vital effect on the flow 


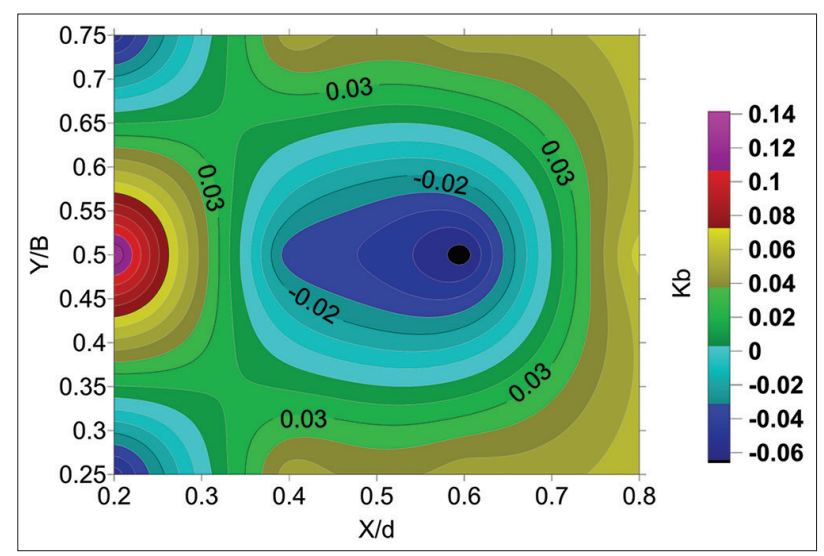

Figure 3: Variation of $\mathrm{Kb}, \theta=15^{\circ}, \frac{\mathrm{Y}}{\mathrm{Y}_{\mathrm{O}}}=10 \%$

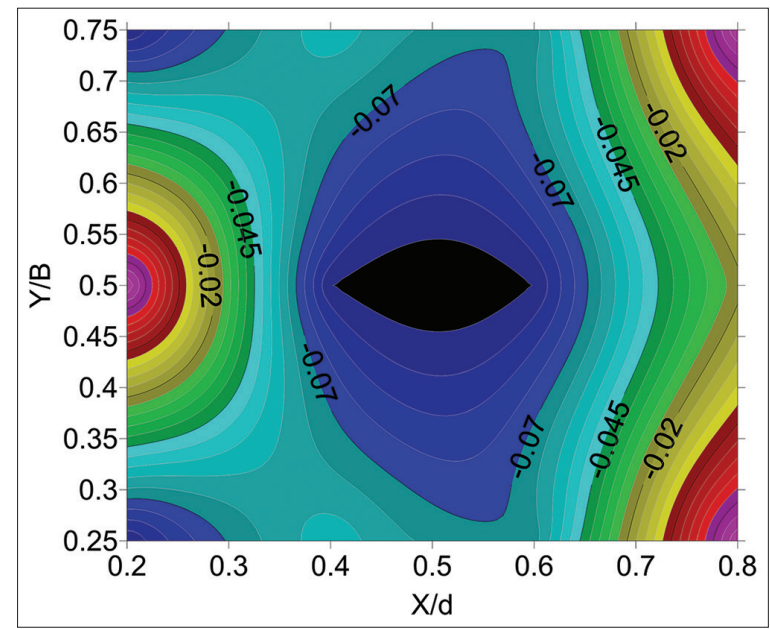

Figure 4: Variation of $\mathrm{Kb}, \theta=15^{\circ}, \frac{\mathrm{Y}}{\mathrm{Y}_{\mathrm{O}}}=20 \%$

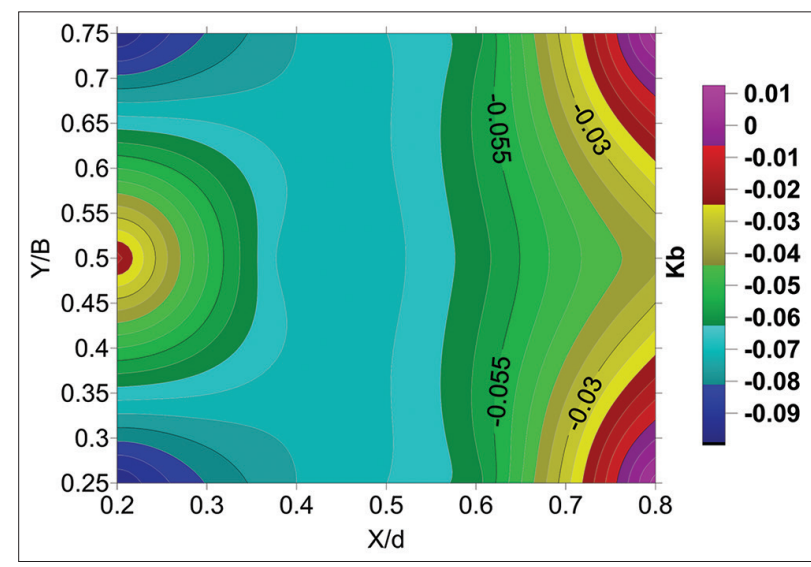

Figure 5: Variation of $\mathrm{Kb}, \theta=15^{\circ}, \frac{\mathrm{Y}}{\mathrm{Y}_{\mathrm{O}}}=30 \%$

behavior beneath the gate so that it is effectively reflected on the increase of $\mathrm{Kb}$ values and caused a recession in negative values for gate openings ( $\mathrm{Y} / \mathrm{Yo} \geq 30 \%$ ), as shown

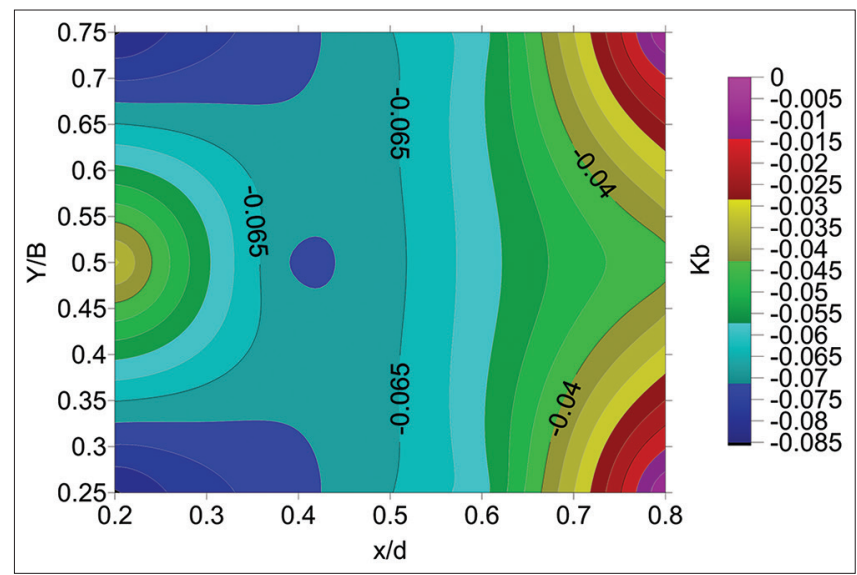

Figure 6: Variation of $\mathrm{Kb}, \theta=15^{\circ}, \frac{\mathrm{Y}}{\mathrm{Y}_{\mathrm{o}}}=40 \%$

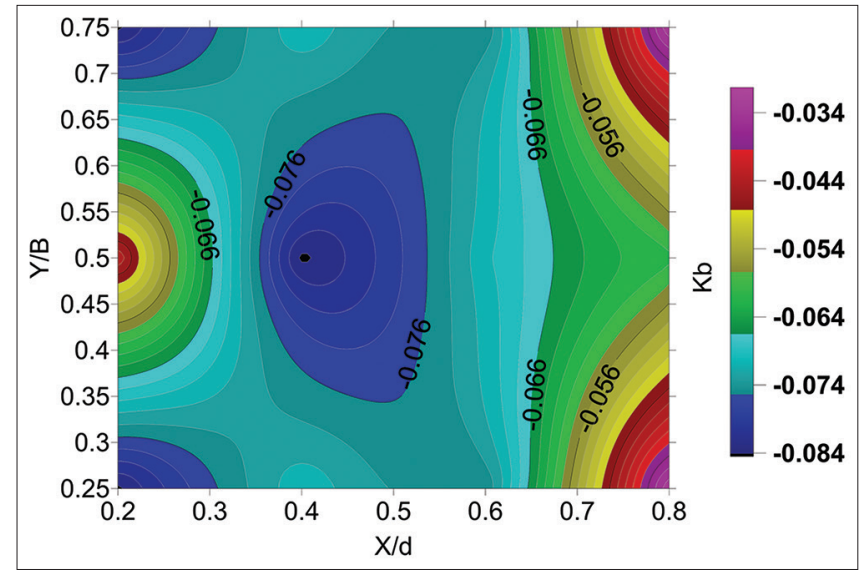

Figure 7: Variation of $\mathrm{Kb}, \theta=15^{\circ}, \frac{\mathrm{Y}}{\mathrm{Y}_{\mathrm{O}}}=50 \%$

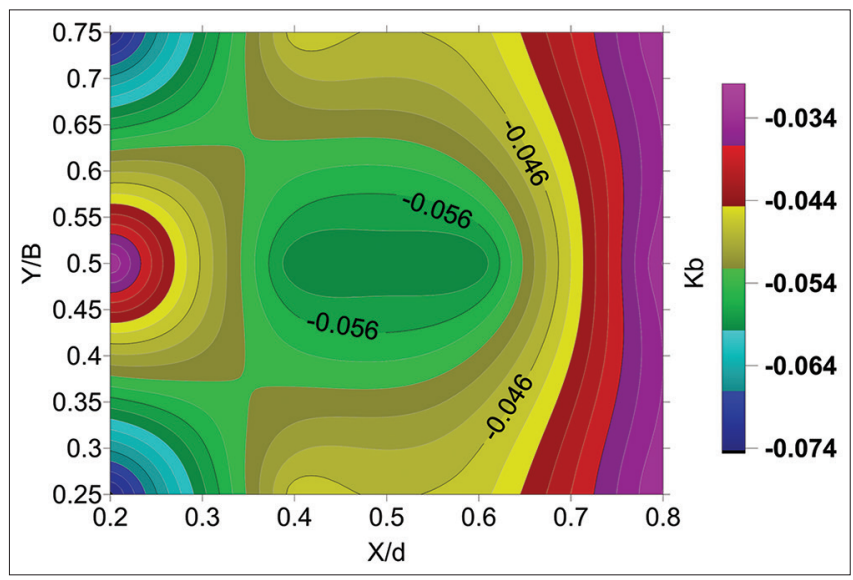

Figure 8: Variation of $\mathrm{Kb}, \theta=15^{\circ}, \frac{\mathrm{Y}}{\mathrm{Y}_{\mathrm{O}}}=60 \%$

in Figures 11-16. For the cases when the gate is slightly opened $(\mathrm{Y} / \mathrm{Yo}<30 \%$ ), the flow velocity issued below the gate is relatively high and consequently accompanied by a 


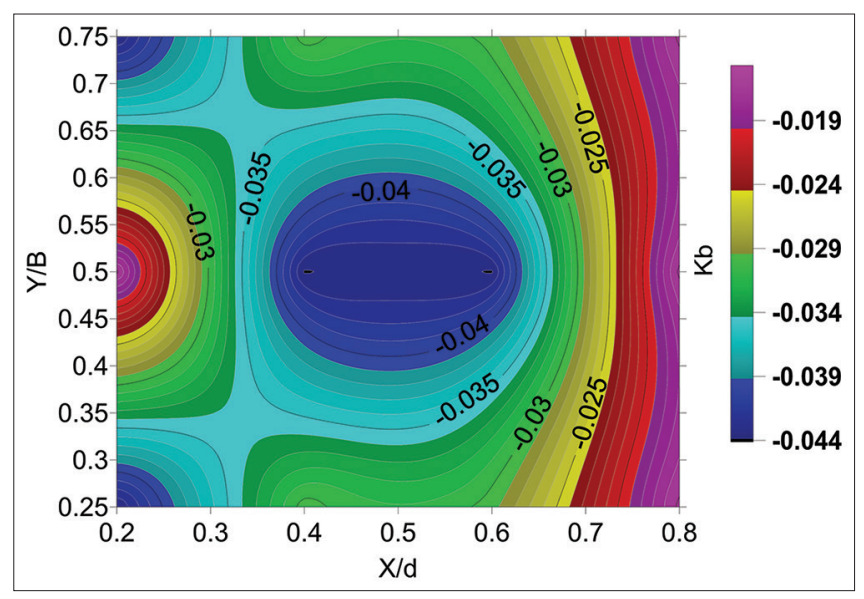

Figure 9: Variation of $\mathrm{Kb}, \theta=15^{\circ}, \frac{\mathrm{Y}}{\mathrm{Y}_{\mathrm{O}}}=70 \%$

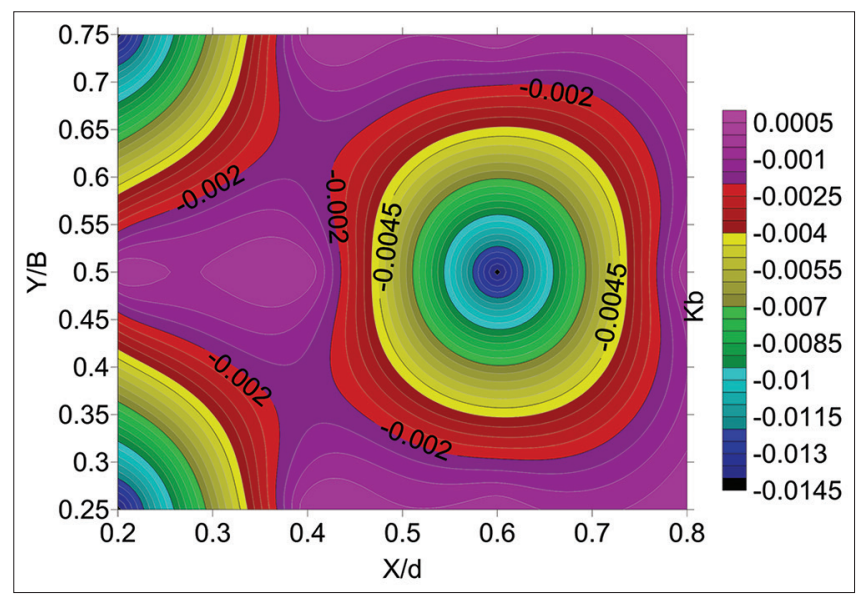

Figure 10: Variation of $\mathrm{Kb}, \theta=15^{\circ}, \frac{\mathrm{Y}}{\mathrm{Y}_{\mathrm{O}}}=80 \%$

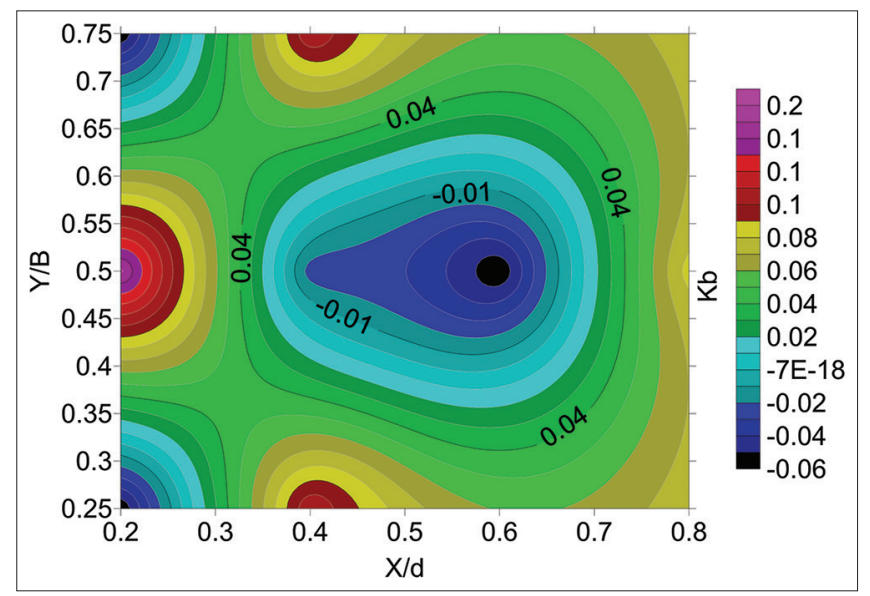

Figure 11: Variation of $\mathrm{Kb}, \theta=15^{\circ},(\mathrm{Q} 2), \frac{\mathrm{Y}}{\mathrm{Y}_{\mathrm{O}}}=30 \%$

reduction in pressure values. This explains the development of negative values and the occurrence of separation; the

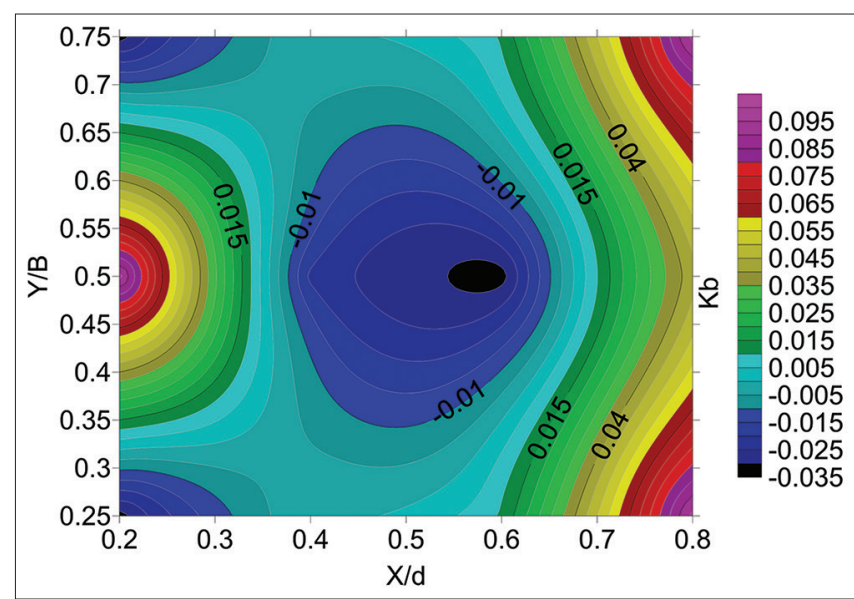

Figure 12: Variation of $K b, \theta=15^{\circ},(Q 2), \frac{Y}{Y_{0}}=40 \%$

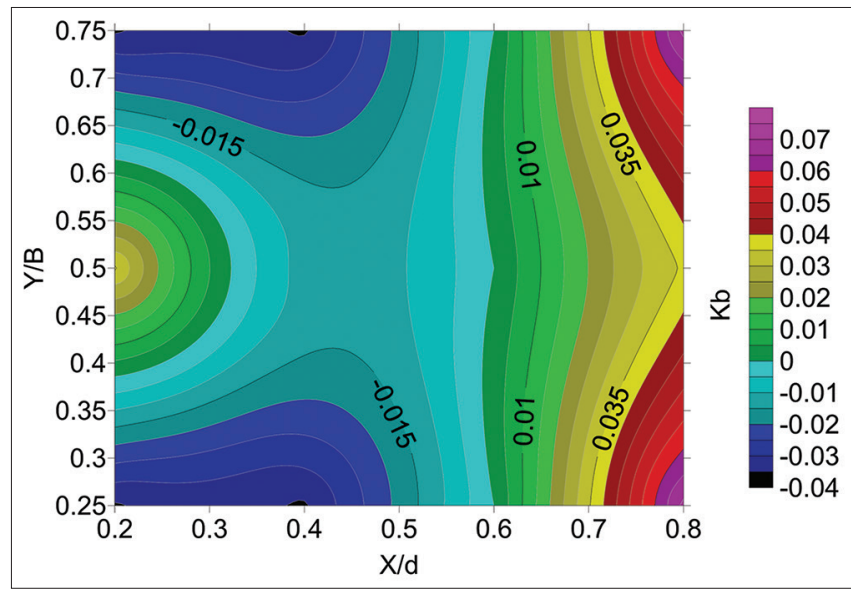

Figure 13: Variation of $\mathrm{Kb}, \theta=15^{\circ},(\mathrm{Q} 2), \frac{\mathrm{Y}}{\mathrm{Y}_{\mathrm{O}}}=50 \%$

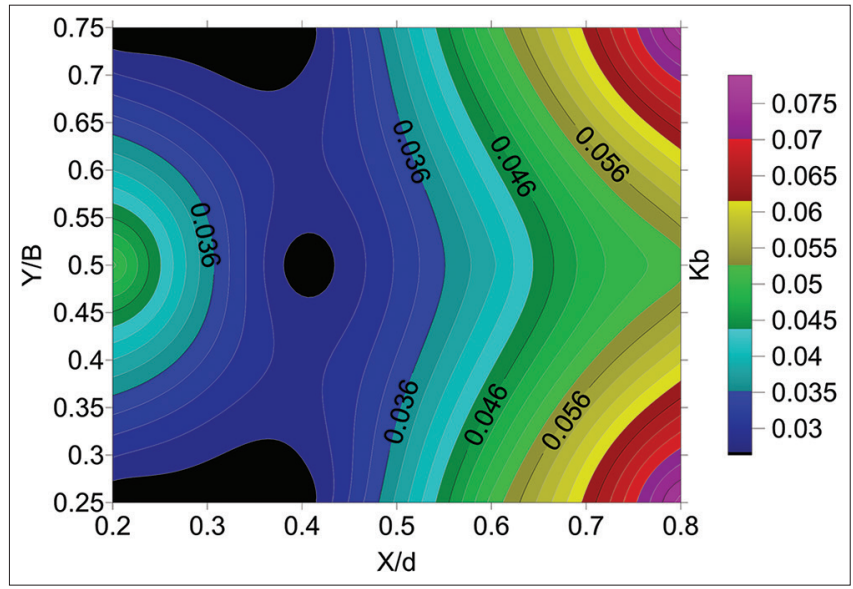

Figure 14: Variation of $\mathrm{Kb}, \theta=15^{\circ},(\mathrm{Q} 2), \frac{\mathrm{Y}}{\mathrm{Y}_{\mathrm{O}}}=60 \%$

latter one is often concentrated in the middle of the gate surface, as shown in Figures 17 and 18. The results show 


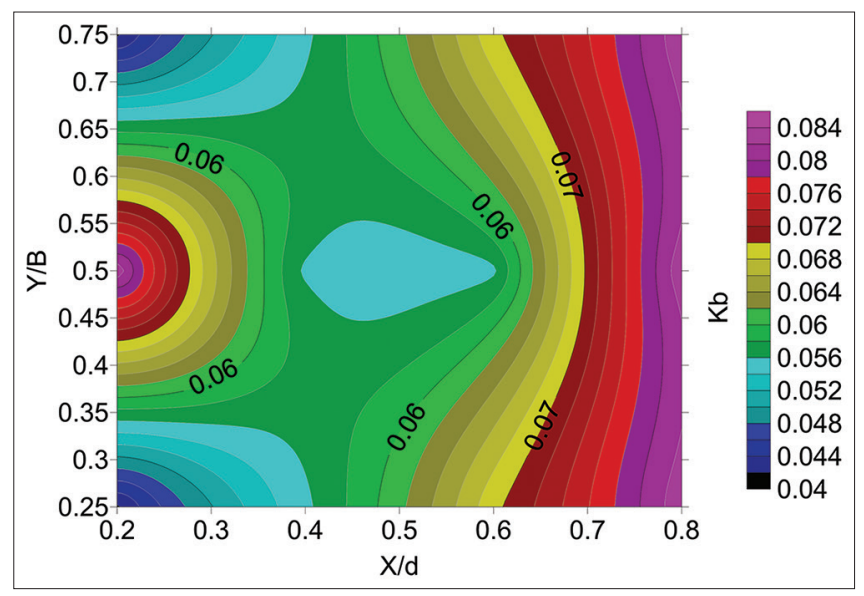

Figure 15: Variation of $\mathrm{Kb}, \theta=15^{\circ},(\mathrm{Q} 2), \frac{\mathrm{Y}}{\mathrm{Y}_{\mathrm{O}}}=70 \%$

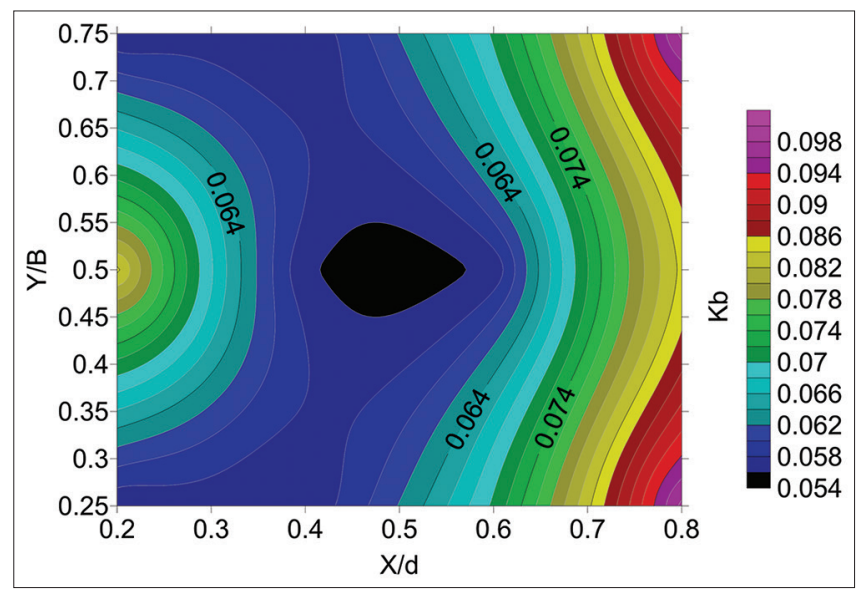

Figure 16: Variation of $\mathrm{Kb}, \theta=15^{\circ},(\mathrm{Q} 2), \frac{\mathrm{Y}}{\mathrm{Y}_{\mathrm{O}}}=80 \%$

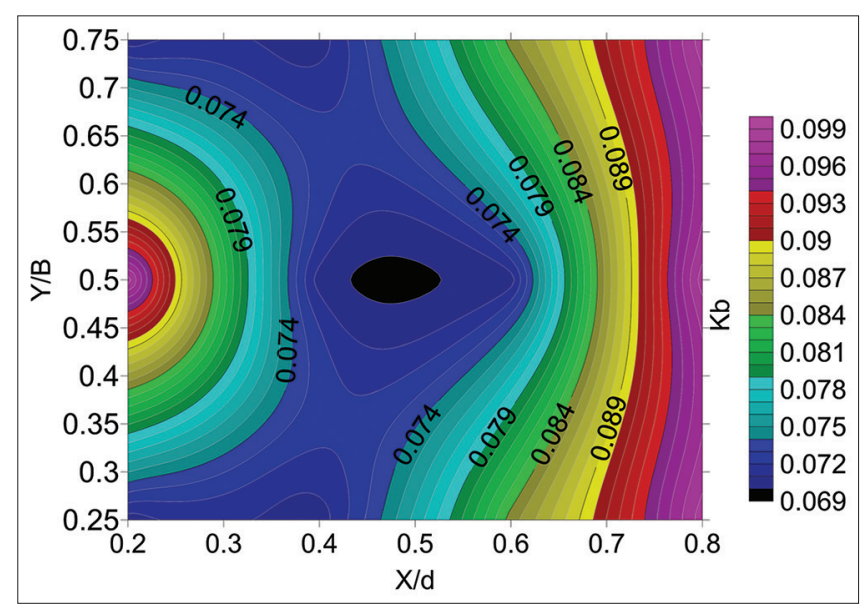

Figure 17: Variation of $\mathrm{Kb}, \theta=15^{\circ},(\mathrm{Q} 2), \frac{\mathrm{Y}}{\mathrm{Y}_{\mathrm{O}}}=10 \%$

that for $\mathrm{Y} / \mathrm{Yo}_{\mathrm{O}}=30 \%$, both sides of gate leading edge up to $\mathrm{X} / \mathrm{D}=0.5$ are covered by low pressure which then after

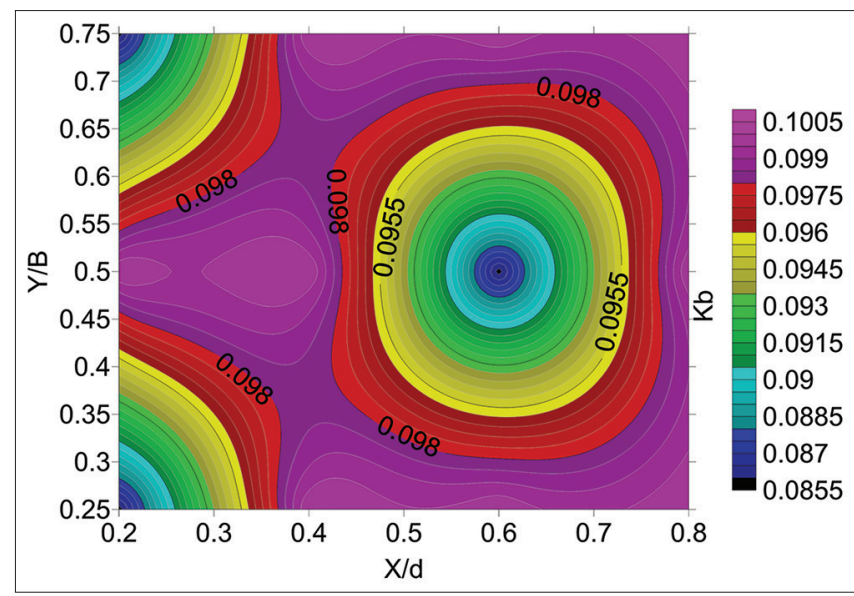

Figure 18: Variation of $\mathrm{Kb}, \theta=15^{\circ},(\mathrm{Q} 2), \frac{\mathrm{Y}}{\mathrm{Y}_{\mathrm{O}}}=20 \%$

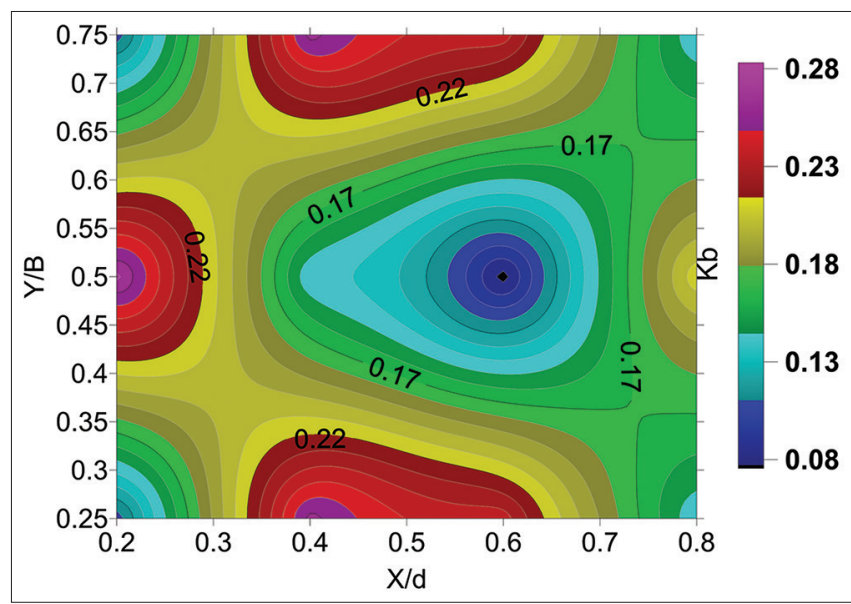

Figure 19: Variation of $\mathrm{Kb}, \theta=20^{\circ}, \frac{\mathrm{Y}}{\mathrm{Yo}}=10 \%$

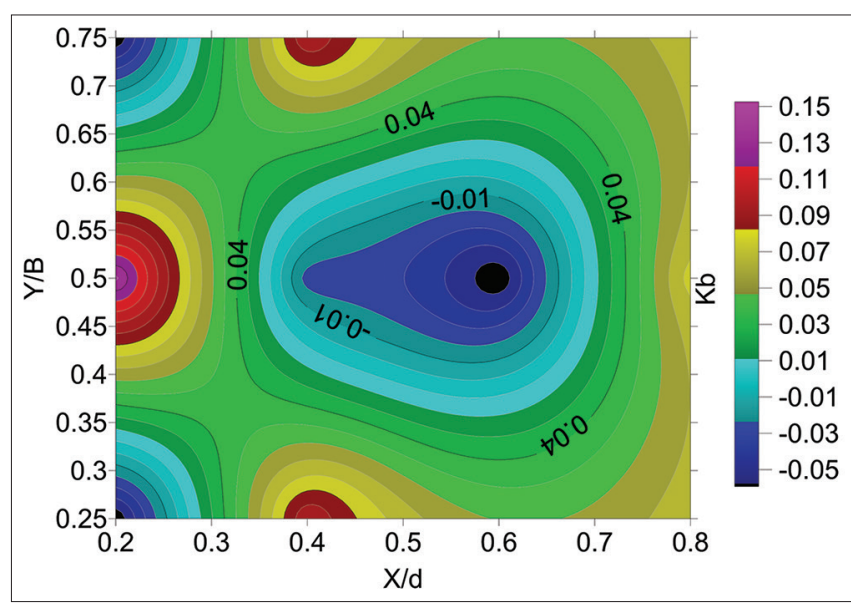

Figure 20: Variation of Kb, $\theta=20^{\circ}, \frac{Y}{Y o}=20 \%$

moved toward the middle zone at $\mathrm{Y} / \mathrm{Yo}=40 \%$. Mostly, high pressure appeared in the middle portion of leading 


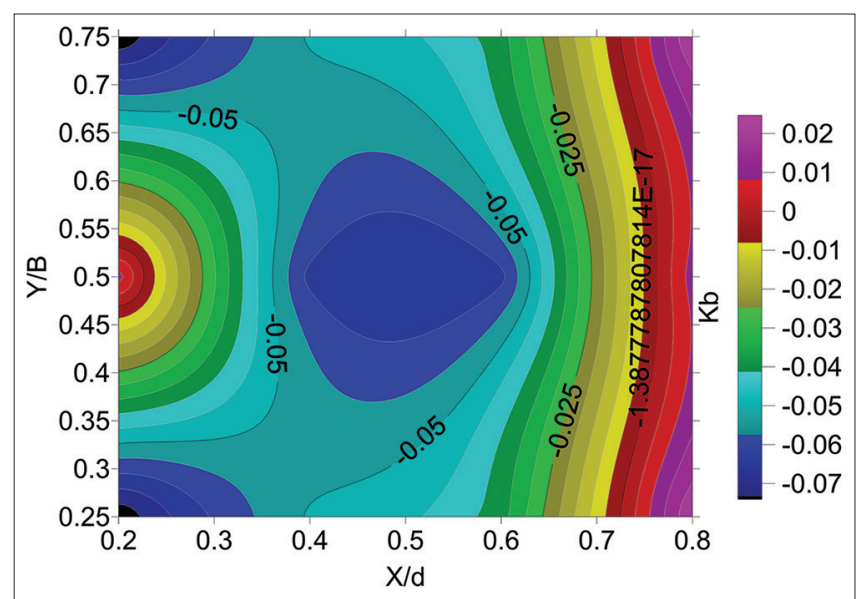

Figure 21: Variation of $\mathrm{Kb}, \theta=20^{\circ}, \frac{\mathrm{Y}}{\mathrm{Yo}}=30 \%$

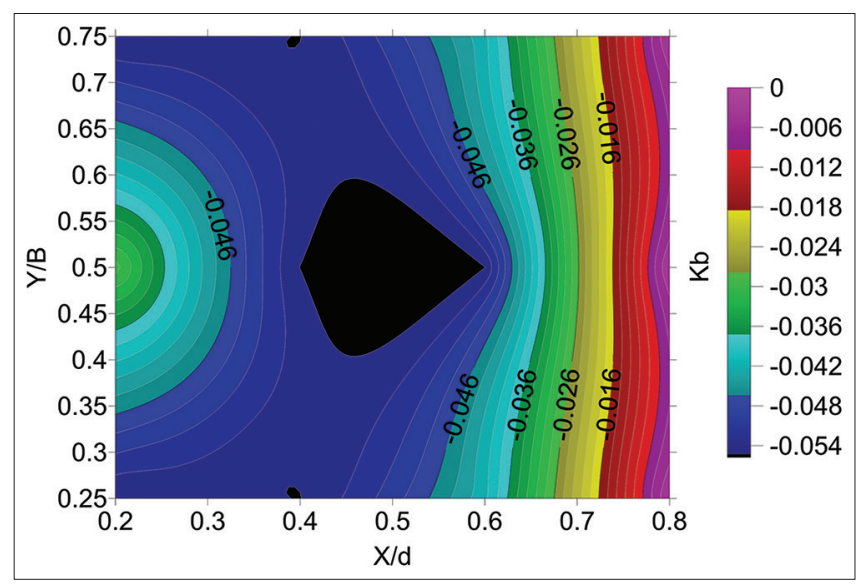

Figure 22: Variation of $\mathrm{Kb}, \theta=20^{\circ}, \frac{\mathrm{Y}}{\mathrm{YO}}=40 \%$

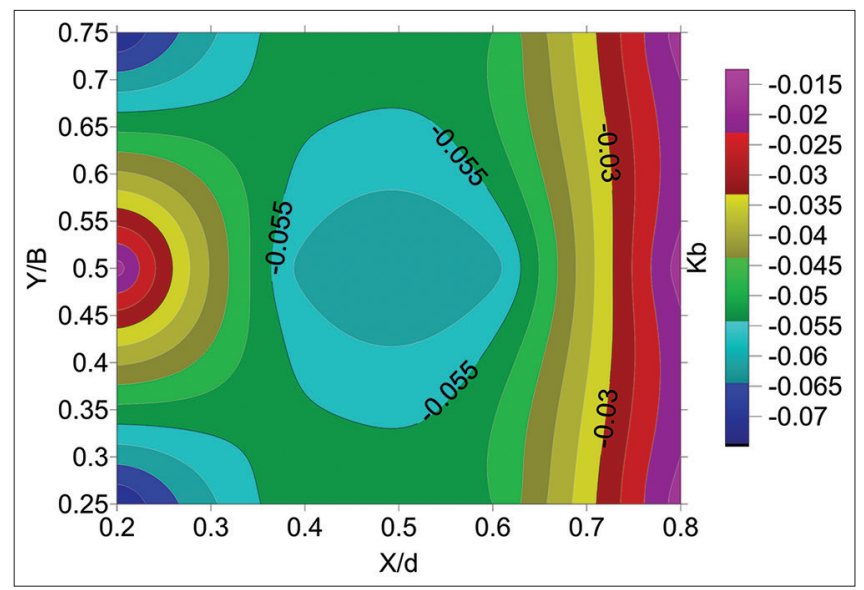

Figure 23: Variation of $\mathrm{Kb}, \theta=20^{\circ}, \frac{\mathrm{Y}}{\mathrm{Yo}}=50 \%$

edge in addition to the zone started from $\mathrm{X} / \mathrm{d}=0.55$ toward the trailing edge. A similar phenomenon was noted

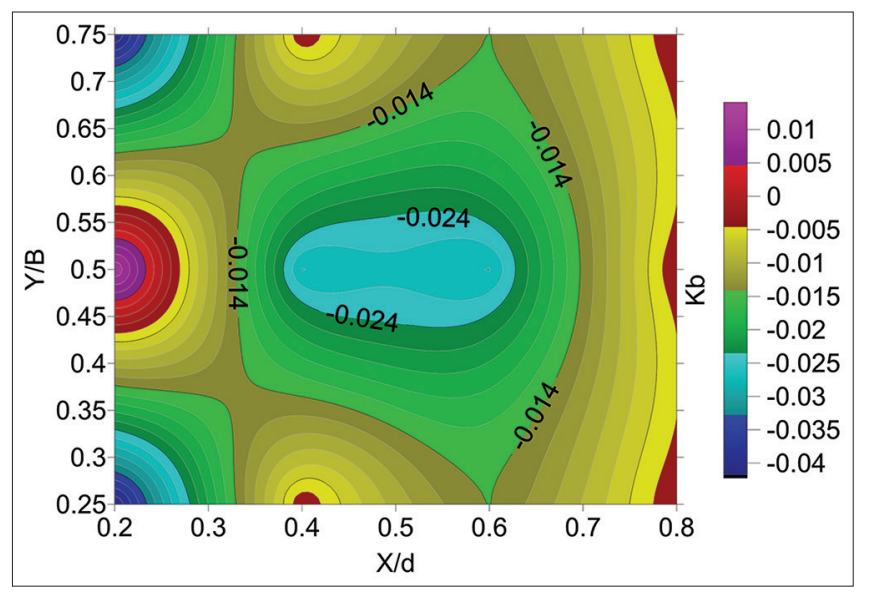

Figure 24: Variation of $\mathrm{Kb}, \theta=20^{\circ}, \frac{\mathrm{Y}}{\mathrm{Yo}}=60 \%$

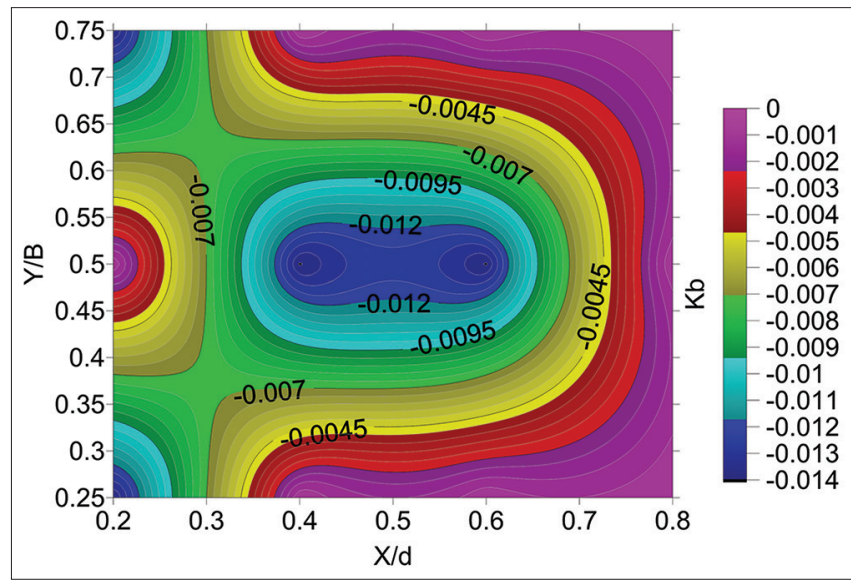

Figure 25: Variation of $\mathrm{Kb}, \theta=20^{\circ}, \frac{\mathrm{Y}}{\mathrm{Yo}}=70 \%$

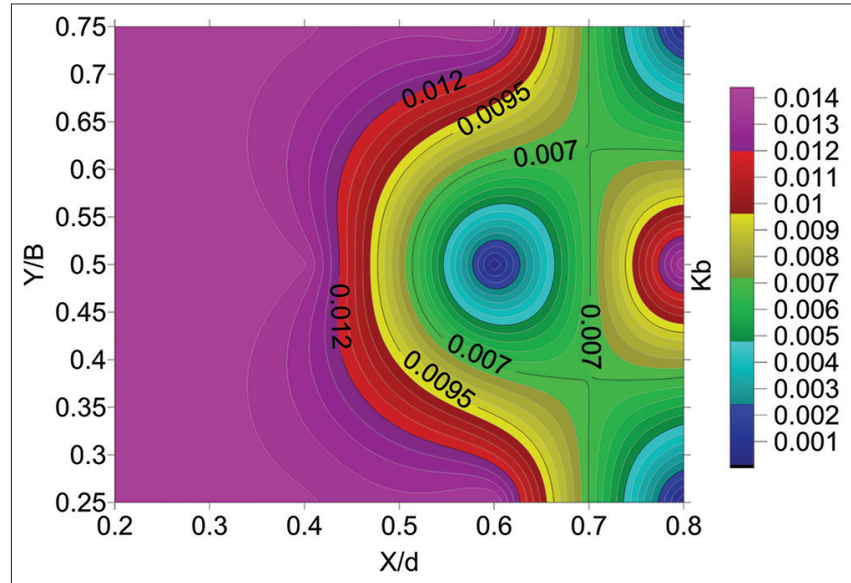

Figure 26: Variation of $\mathrm{Kb}, \theta=20^{\circ}, \frac{\mathrm{Y}}{\mathrm{Yo}}=80 \%$

at larger gate openings (up to $\mathrm{Y} / \mathrm{Yo}=70 \%$ ) beyond which a little difference in pressure values is indicated for the whole 
gate surface. A general conclusion may be stated that for $\mathrm{Y} / \mathrm{Yo} \geq 30 \%$, the behavior of flow is alternated slightly from strong to weak attachment, hence, insignificant vibration can be expected and the gate in a stable mode.

\section{Bottom Pressure Coefficient for Gate Lip Shape $\left(\theta=20^{\circ}\right)$}

The effect of gate lip shape $\left(\theta=20^{\circ}\right)$ on magnitude and distribution of $\mathrm{Kb}$ was investigated and the results are shown in Figures 19-26. It is shown from Figures 19 and 20 that for small gate openings, all the values of $\mathrm{Kb}$ are positive and mostly varied uniformly from high values on bounded zones to low values toward the middle zone bounded by $\mathrm{X} / \mathrm{d}$ from 0.55 to 0.65 for $\mathrm{Y} / \mathrm{Yo}=10 \%$ and 0.4 to 0.65 for $\mathrm{Y} / \mathrm{Yo}=20 \%$. As the value of $\mathrm{Y} / \mathrm{Yo}$ is increased (from $>20 \%$ up to $70 \%$ ), the values of $\mathrm{Kb}$ are decreased to negative and again the lowest values were in the middle zone of the gate surface. For $\mathrm{Y} / \mathrm{Yo}_{\mathrm{O}}>70 \%$, the $\mathrm{Kb}$ values were positive and low.

\section{CONCLUSIONS}

In this study, the pressure distribution on the shapes of the gate lips was measured using a random hydraulic model and displayed as contour maps for the different gate openings. The main factors affecting the bottom pressure factor $(\mathrm{KB})$ (BPC) were investigated and the following conclusions can be drawn:

1. For gate lip shape $\left(\theta=15^{\circ}\right)$, the pressure intensity is found to be relatively high for small and high gate openings. For the rest gate openings, the pressures are less in values and even negative, moreover, the flow pattern continues to show separation mode with no significant fluctuation is indicated which may put the gate in nearly stable mode

2. The observation reveals that for all gate openings, the lowest values of pressure intensity were located in the middle zone of the bottom gate surface and pocket of vortices may be established

3. The increase of discharge for gate lip shape $\left(\theta=15^{\circ}\right)$ causes a substantial increase in pressure and approximately eliminated the negative pressure values, especially for gate openings ( $/$ Yo $\geq 30 \%)$. Hence, the downpull force which has been considered as a major indicator for gate stability increases and may threaten the gate operation. Besides, the behavior of flow showed a slight alternate from strong to weak attachment, hence, insignificant vibration can be expected, and the gate is mostly in a stable mode

4. For $\theta=20^{\circ}$, the results showed that for small gate openings, all values of pressure coefficient $(\mathrm{Kb})$ are positive and relatively high on gate boundary which then mostly dropped uniformly toward the middle zone. Whereas, as $\mathrm{Y} /$ Yo value increases (up to $70 \%$ ), the values of $\mathrm{Kb}$ decrease to negative and again the lowest values are located in the middle zone of the gate surface. The results also showed that for $\mathrm{Y} / \mathrm{Yo}$ $>70 \%$, the $\mathrm{Kb}$ values returned to be positive and low

5. The presence of a dominant low-pressure zone which is distinct in the middle of the bottom gate surface indicates the critical design conditions.

6. The selected gate shape angles are small and showed that the tendency of flow toward separation seems to be considerably reduced which coincides with some previous conclusions found by Bhargava and Narasimhan, 1989.

\section{REFERENCES}

Ahmed, T. M. 1999. Effect of Gate Lip Shapes on the Downpull Force in Tunnel Gates, Ph. D. Thesis Submitted to the College of Engineering. University of Baghdad, Iraq.

Ahmed, T. M. 2016. Experimental study of pressure coefficient along inclined bottom surface of dam Tunnel gate. Euras. J. Sci. Eng. 1(2): $52-53$.

Alhashimi, S. A., M. T. Al-Kifae and R. M. Almaini. 2010. Prediction downpull force on tunnel gate with different gate lip geometry. J. Kerbala Univ. 8(4): 273-288.

Bhargava, V. P. and S. Narasimhan. 1989. Pressure fluctuations on gates. J. Hydraul. Res. 27: 215-231.

Donald, C. 1959. Hydraulic downpull forces on high head gates. J. Hydraul. Div. 85(11): 39-52.

Drobir, H., V. Kienberger and K. Seyerl. 2001. Downpull on Tunneltype High-head Leaf Gates. In: Proceedings of the Congress International Association for Hydraulic Research. p473-478.

Elder, R. A. and J. M. Garrison. 1964. Form-induced hydraulic forces on three-leaf intake gates. J. Hydraul. Div. 90: 215-233.

Khosrojerdi, A. 2012. Hydraulic studies of pressure distribution around vertical lift gates. Indian J. Sci. Technol. 5(3): 2268-2272.

Naudascher, E., H. Kobus and R. P. R. Rao. 1964. Hydrodynamic analysis for high-head leaf gates. J. Hydraul. Div. 90(3): 155-192.

Naudascher, E. 1991. Hydrodynamic Forces. Structure Design Manual, International Association of Hydro Research, Stockholm, Sweden.

Peter, M. S. and M. J. Garrison. 1964. Hydraulic Downpull on ICE Harbor Power Gate. $3^{\text {rd }}$ ed. A Water Resources Technical, United states.

Sagar, B. 1978. Prediction of Gate Shaft Pressure in Tunnel Gate. Water Power and Dam Construction, United states.

Sagar, B. T. A. 1977. Downpull in High-head Gate Installations. Colorado State University, Colorado.

Thang, N. D. 1990. Gate vibrations due to unstable flow separation. J. Hydraul. Eng. 116: 342-361.

Thang, N. D. and E. Naudascher. 1983. Approach-flow effects on downpull of gates. J. Hydraul. Eng. 2016: 1521-1539.

Uysal, M. A. 2014. Prediction of Downpull on High Head Gates Using Computational Fluid Dynamics, Master's Thesis, PhD Thesis. Middle East Technical University, Turkey. 